\title{
Desenvolvimento e desempenho de um fixador flexível na consolidação de fraturas diafisárias transversais provocadas iatrogênicamente na tíbia de carneiros
}

\author{
Development and performance of a flexible fixator on bone healing of transverse diaphyseal fracture \\ caused iatrogenically in the sheep tibiae
}

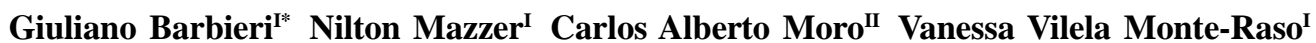 \\ Rodrigo Okubo ${ }^{I}$ Cláudio Henrique Barbieri ${ }^{I}$
}

\section{RESUMO}

Foi realizado um estudo experimental sobre o desenvolvimento e desempenho de um fixador externo flexível no processo de consolidação de tíbias de carneiros submetidas à osteotomia transversa mediodiafisária. Foram empregados no estudo 20 carneiros da raça Santa Inês, com massa corporal média de $37 \mathrm{~kg}$, divididos em diferentes grupos conforme o período de observação pós-operatória, de 30, 45, 60 e 90 dias. Ao final, os animais sofreram a eutanásia e as tíbias foram removidas para estudo de volumetria transversal do calo ósseo por tomografia computadorizada e ensaio mecânico destrutivo. Os resultados mostraram que ocorreu a formação de calo ósseo volumoso, caracterizando assim a ocorrência de deslocamento de carga axial para o foco da osteotomia, promovida pelo fixador externo utilizado. No ensaio mecânico, observou-se que as comparações entre os grupos respectivos intactos e operados foram significantemente diferentes $(P<0,05)$, com exceção do grupo com 90 dias, demonstrando haver rigidez equivalente ao osso normal. Em nenhum dos animais, houve desenvolvimento de pseudoartroses ou não união óssea. Diante dos resultados, conclui-se que o uso do fixador com haste flexível abordado nesta pesquisa para o tratamento de fraturas dos ossos longos de animais de médio porte foi de fácil aplicação, reprodutível e recomendável.

Palavras-chave: carneiro, fixação externa flexível, consolidação, formação de calo ósseo.

\section{ABSTRACT}

An experimental study was carried out to verify the development and performance of a flexible external fixator on the bone healing process of the tibia of sheep submitted to a transverse diaphyseal osteotomy. It was used twenty Santa Inês sheep with average weigh of $37 \mathrm{~kg}$ divided in groups, according to the period of postoperative observation of 30, 45, 60 and 90 days. At the end, the animals were sacrificed and the tibiae were removed for study of transverse callus volumetric by computed tomography and destructive mechanical testing. The results had shown that the formation of voluminous callus occurred, thus characterizing the occurrence of displacement of axial load to the focus of the osteotomy, promoted by the used external fixator used. The mechanical testing showed that the comparisons between the respective intact and operated groups were significantly different $(P<0.05)$ except for the group with 90 days, which demonstrated equivalent stiffness when compared to normal bone. In none of the animals there was development of pseudarthrosis or non-union of the bone. Given the results, it was conclude that the use of the flexible fixator covered in this research for treatment of long bones fractures in medium animals was easy to apply, reproducible and recommended.

Key words: sheep, flexible external fixation, bone healing, callus formation.

\section{INTRODUÇÃO}

Os fixadores externos foram introduzidos na Medicina Veterinária em 1937. Como inovação para conferir uma maior estabilidade à fixação, apenas um dos pinos era introduzido transversalmente ao osso, sendo o outro introduzido obliquamente, realizandose este procedimento nas duas extremidades da fratura. Sua indicação se faz em diversos tipos de fraturas e

'Departamento de Biomecânica, Medicina e Reabilitação do Aparelho Locomotor, Faculdade de Medicina de Ribeirão Preto (FMRP), Universidade de São Paulo (USP), 14049-900, Ribeirão Preto, SP, Brasil. E-mail: gibieri@yahoo.com.br. *Autor para correspondência.

IILaboratório de Bioengenharia, FMRP-USP, Ribeirão Preto, SP, Brasil. 
também nas expostas e em pseudoartrose (FOSSUM et al., 2002) Para a obtenção do máximo de benefício dos fixadores externos, é necessário deter conhecimentos básicos da biomecânica desses aparelhos e da carga fisiológica através do foco da fratura (WU et al., 1984; WOLF et al., 1998).

A consolidação de fraturas pode ser direta, de um fragmento ósseo para o outro, ou indireta, com a formação do calo. No primeiro caso, é preciso que haja imobilização perfeita, por meio de fixação rígida, o que só é obtido por meio das placas de compressão. No segundo, a imobilização é relativa e a fixação é dita flexível, situação em que se forma um calo ósseo mais ou menos volumoso, dependendo do grau de rigidez da montagem; é o que ocorre com os fixadores externos (WU et al., 1984). O calo ósseo se estabelece pela formação de dois colares periosteais, um em cada segmento do osso fraturado, que gradualmente se aproximam um do outro e se fundem, até que a consolidação seja estabelecida. Os micro-movimentos interfragmentários, sob condições controladas, podem induzir a formação de um calo periosteal volumoso, inclusive acelerando o processo de reparo da fratura (DE BASTIANI et al., 1984; WU et al., 1984).

Nas fraturas instáveis, a associação de movimentos laterais associados aos axiais pode levar a não consolidação. No entanto, movimentos axiais de até $0,5 \mathrm{~mm}$ no foco da fratura, na ausência de movimentos laterais, contribuem para a formação do calo ósseo (WOLF et al., 1998; CLAES et al., 2000; AUGAT et al., 2001). CLAES et al. (1997) demonstraram que a consolidação óssea foi melhor em osteotomia transversal da diáfise do metatarsiano de ovelhas, com espaçamento de até $2 \mathrm{~mm}$, por proporcionar mobilidade axial, sem movimentos laterais. Em pacientes humanos, com diferentes fraturas da diáfise da tíbia, estabilizadas com fixador externo unilateral que proporcionava um determinado grau de flexibilidade, observou-se que as fraturas simples apresentaram excelente processo de união, com doze semanas de tratamento e, nas fraturas complexas, foi necessário um período de vinte e seis semanas para que ocorresse consolidação adequada (SCHMIDT \& RORABECK, 1983).

Contudo, este estudo teve como objetivos desenvolver e testar um fixador externo semi-flexível, que permitisse a ocorrência de micro-movimentos controlados e a transmissão da carga ao foco da fratura, visando a obter um calo ósseo mais volumoso, no intuito de favorecer o processo de consolidação, num modelo de osteotomia transversal da tíbia de carneiros. Os resultados foram avaliados qualitativamente, por meio de radiografias convencionais e quantitativamente pela tomografia computadorizada e ensaio mecânico destrutivo.

\section{MATERIAL E MÉTODOS}

Foram utilizados 20 carneiros da raça Santa Inês de dez meses de idade, com massa corporal média de $37 \mathrm{~kg}$. Após o período de avaliação, em que receberam cuidados veterinários, incluindo vermifugação e revisão dos cascos para evitar defeitos de aprumo, os animais considerados aptos foram submetidos à cirurgia e mantidos isolados por um período de cinco dias no laboratório. A dieta durante todo o período experimental constou de ração ovina balanceada, sal mineral, capim, feno selecionado e água ad libitum.

Optou-se pelo modelo de osteotomia transversal da tíbia direita, que provê maior estabilidade à montagem, sendo o mais adequado para os propósitos da pesquisa. Os animais foram distribuídos em quatro grupos (com cinco animais cada), conforme o período de observação pós-operatória, de 30, 45, 60 e 90 dias.

As hastes dos fixadores foram confeccionadas com tubos ocos de alumínio de $19 \mathrm{~mm}$ de diâmetro e $0,9 \mathrm{~mm}$ de espessura das paredes. Dois segmentos de $90 \mathrm{~mm}$ de comprimento foram cortados do tubo e encaixados nas extremidades de uma peça cilíndrica de náilon de $60 \mathrm{~mm}$ de comprimento por 19mm de diâmetro (flexibilizador) (Figura 1A), torneadas para se encaixarem sob pressão no interior dos tubos, mas deixando exposto um segmento de $11 \mathrm{~mm}$ de comprimento da peça cilíndrica de náilon, localizado entre os dois tubos ocos de alumínio (Figura 1B). Nesse segmento, foram feitas três ranhuras circunferenciais de $3 \mathrm{~mm}$ de profundidade, cuja finalidade foi tornar o fixador mais flexível. Quatro presilhas confeccionadas em alumínio (Figura 1C) foram montadas no fixador, duas de cada lado dos tubos ocos de alumínio para conexão com os fios de Schanz (Trautec Equipamentos Cirúrgicos LTDA ${ }^{\circledR}$, Ribeirão Preto - SP, Brasil) de 4mm de diâmetro (Figura 1D), que foram as únicas partes introduzidas nos ossos (Figura 2F). Foram realizados ensaios mecânicos para demonstrar o quanto de carga era necessário para um deslocamento axial de $1 \mathrm{~mm}$ da haste flexível. Utilizou-se uma haste rígida do mesmo material (alumínio) da haste flexível, mas sem o dispositivo de náilon central como comparativa. Foi necessária uma carga de $77 \mathrm{~N}$ para a haste flexível, enquanto que, para haste rígida, uma carga aproximada de $134 \mathrm{~N}$.

Os animais foram operados sob anestesia geral, sem intubação traqueal. Na pré-anestesia, utilizouse acepromazina $\left(0,1 \mathrm{mg} \mathrm{kg}^{-1}\right)$ associada à xilazina $(0,1 \mathrm{mg}$ $\mathrm{kg}^{-1}$ ) e tramadol $\left(2 \mathrm{mg} \mathrm{kg}^{-1}\right)$, por via intravenosa. A indução anestésica foi feita com quetamina (3mg kg-1) por via intravenosa e a manutenção anestésica, com uma associação de quetamina $\left(1 \mathrm{~g} \mathrm{~L}^{-1}\right)$, éter gliceril- 


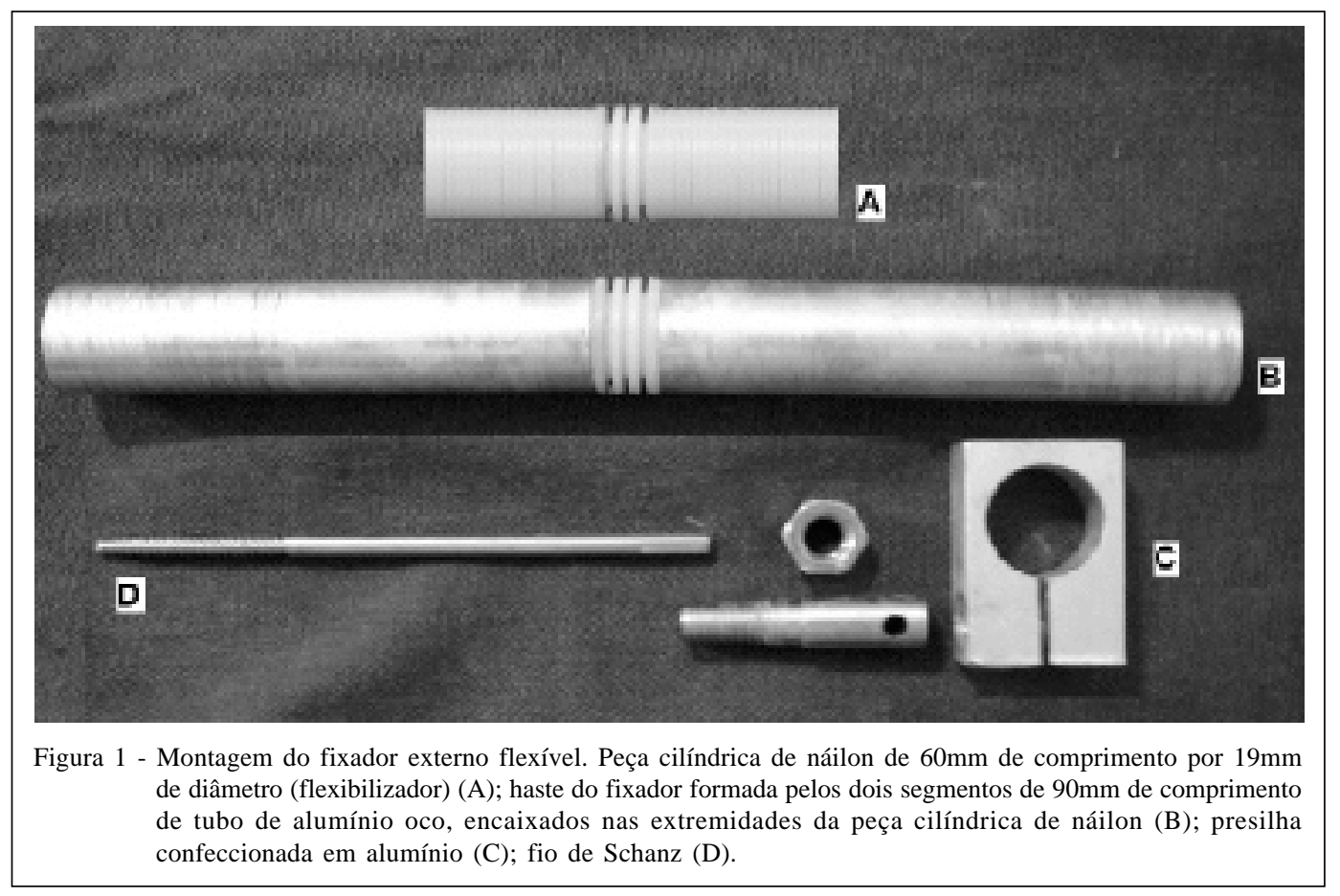

guaiacol (50g L $\left.\mathrm{g}^{-1}\right)$ e xilazina (100mg L-1 $)$, diluídos em solução fisiológica $0,9 \%$, infundidos com velocidade de $3 m L k^{-1} h^{-1}$.

A tíbia foi abordada em sua face ânteromedial. Foi marcado o ponto médio da tíbia, definido como o meio da distância entre o ponto mais proeminente do côndilo medial e o maléolo lateral, acompanhando o eixo longitudinal do osso. Inicialmente, quatro fios de Schanz foram introduzidos percutaneamente, sendo cada um a $4 \mathrm{~cm}$ do outro, em direção perpendicular, com o auxílio de um gabarito, que consistia num tubo de alumínio adequadamente perfurado (Figura 2A,B,C). Foram feitas incisões de $1 \times 1 \mathrm{~cm}$ nos locais de introdução dos fios e dissecação romba do subcutâneo, até o plano ósseo. Depois, perfurou-se um orifício, com broca de $3 \mathrm{~mm}$ de diâmetro, nas duas corticais diametralmente opostas. Os quatro fios foram passados manualmente, para evitar a osteólise térmica, e o fixador conectado e os parafusos, apertados. Em seguida, a tíbia foi abordada por meio de uma incisão longitudinal de $3 \mathrm{~cm}$ de comprimento entre os dois fios de Schanz centrais (Figura 2D), na pele, subcutâneo e periósteo, o qual foi parcialmente descolado do osso. Realizou-se a osteotomia transversal com uma serra motorizada vibratória, de 1mm de espessura (Figura 2E) e a ferida cirúrgica foi suturada por planos, sendo o periósteo e o plano muscular com fio absorvível 3-0 de poliglactina 910 e a pele com náilon 2-0 monofilamentar (Figura 2F). Foram instituídas antibioticoterapia profilática (penicilina 40.000UI $\mathrm{kg}^{-1}$ - dose única) e analgesia (cetoprofeno, $2 \mathrm{mg} \mathrm{kg}^{-1}$ ) por via intramuscular, SID, por cinco dias consecutivos.

Exames radiográficos convencionais foram obtidos em dois planos (ântero-posterior e lateral) no pós-operatório imediato e a cada 15 dias para visualização do processo de consolidação e da continuidade do perfeito alinhamento da osteotomia. Ao final do período de observação de cada grupo, os animais foram eutanasiados com uma dose letal do anestésico tiopental sódico e as tíbias foram removidas para estudo de volumetria transversal do calo ósseo por tomografia computadorizada e ensaio mecânico destrutivo de flexão em três pontos.

As avaliações pela tomografia computadorizada foram realizadas no aparelho-padrão (Siemens ${ }^{\circledR}$ - Somaton emotion helicoidal) do Hospital das Clínicas da FMRP-USP. As tíbias foram posicionadas aos pares, tíbia intacta e tíbia operada de cada animal, lado a lado, com as cristas perpendiculares ao plano horizontal da mesa do aparelho de tomografia. Para a obtenção das imagens, foi utilizado o protocolo para laringe (130kV e $125 \mathrm{~mA})$, sendo feitos em média vinte e seis cortes transversais de $1 \mathrm{~mm}$ de largura sobre a região de interesse para o cálculo da volumetria (Figura 3). Utilizou-se o princípio de Cavalieri (GARCÍAFINÃNA et al., 2003), em que o volume de um corte (fatia) de aquisição pode ser calculado como o produto 


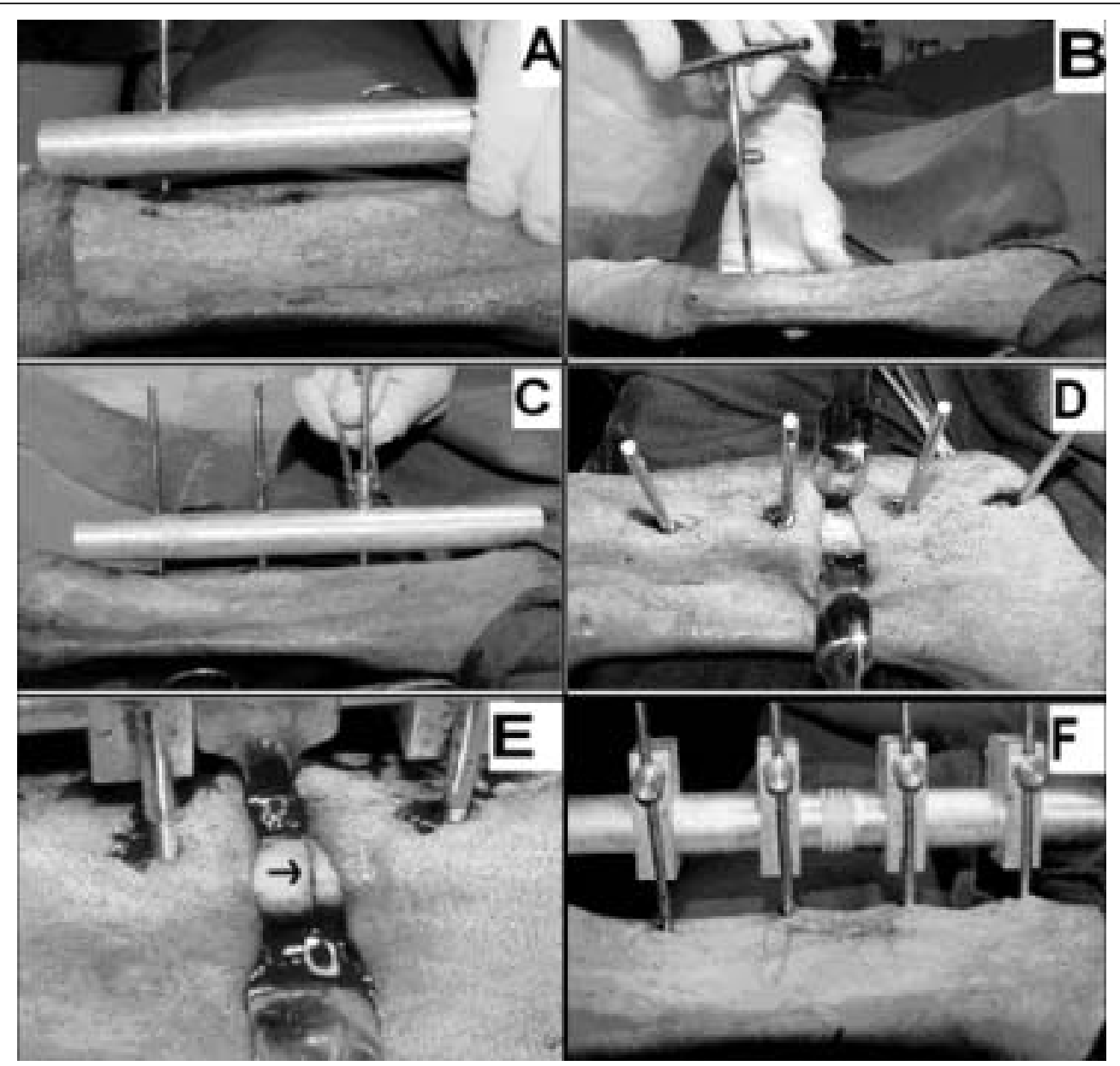

Figura 2 - Procedimento cirúrgico. Utilização de um guia gabarito para a passagem dos fios (pinos) (A); passagem dos fios (B e C); acesso cirúrgico para a osteotomia (D); osteotomia na diáfise da tíbia (E); osteotomia reduzida com fixador externo flexível (F).

da área da estrutura no corte, pela espessura do corte. O valor encontrado do volume do calo periosteal foi dividido pelo valor do volume do osso intacto contralateral do mesmo animal, resultando na porcentagem do volume de calo formado. Com isso, obteve-se a porcentagem média para cada grupo.

Para realização do ensaio mecânico, utilizouse uma célula de carga de $1000 \mathrm{kgf}$, acoplada em uma máquina universal de ensaios (EMIC ${ }^{\circledR}$, modelo DL10000, São José dos Pinhais - PR, Brasil), presente no Laboratório de Bioengenharia da FMRP-USP. Foram usados também apoios inferiores, com distância de 130mm entre eles, para o apoio da tíbia. A carga foi aplicada superiormente, no centro do osso, por um acessório com a extremidade torneada e abaulada, com a finalidade de não haver penetração. Os parâmetros do ensaio mecânico consistiram de: velocidade de aplicação de carga de $1 \mathrm{~mm} \mathrm{~min}^{-1}$, pré-carga de $100 \mathrm{~N}$, havendo detecção do colapso em $50 \%$ da força máxima. A propriedade mecânica analisada foi a força no limite máximo (ou força máxima).

Para a realização da análise estatística, utilizou-se o software GraphPad Prism ${ }^{\circledR}$ versão 5.0. Os dados obtidos, nas análises tomográficas e mecânicas, foram processados pelo programa, de modo a verificar sua normalidade (demonstrando-se perfazer um modelo de curva de Gauss), verificando se apresentavam valores paramétricos ou não-paramétricos. A partir dessas análises, constando dados paramétricos, utilizou-se do teste de variância ANOVA One-Way e o pós-teste de Tukey para as comparações intra-grupos. Para comparação entre dados dos ossos intactos e operados, utilizou-se o teste T-student para a análise intergrupos. Para todos os testes, o nível de significância foi de $\mathrm{P}<0,05$. 


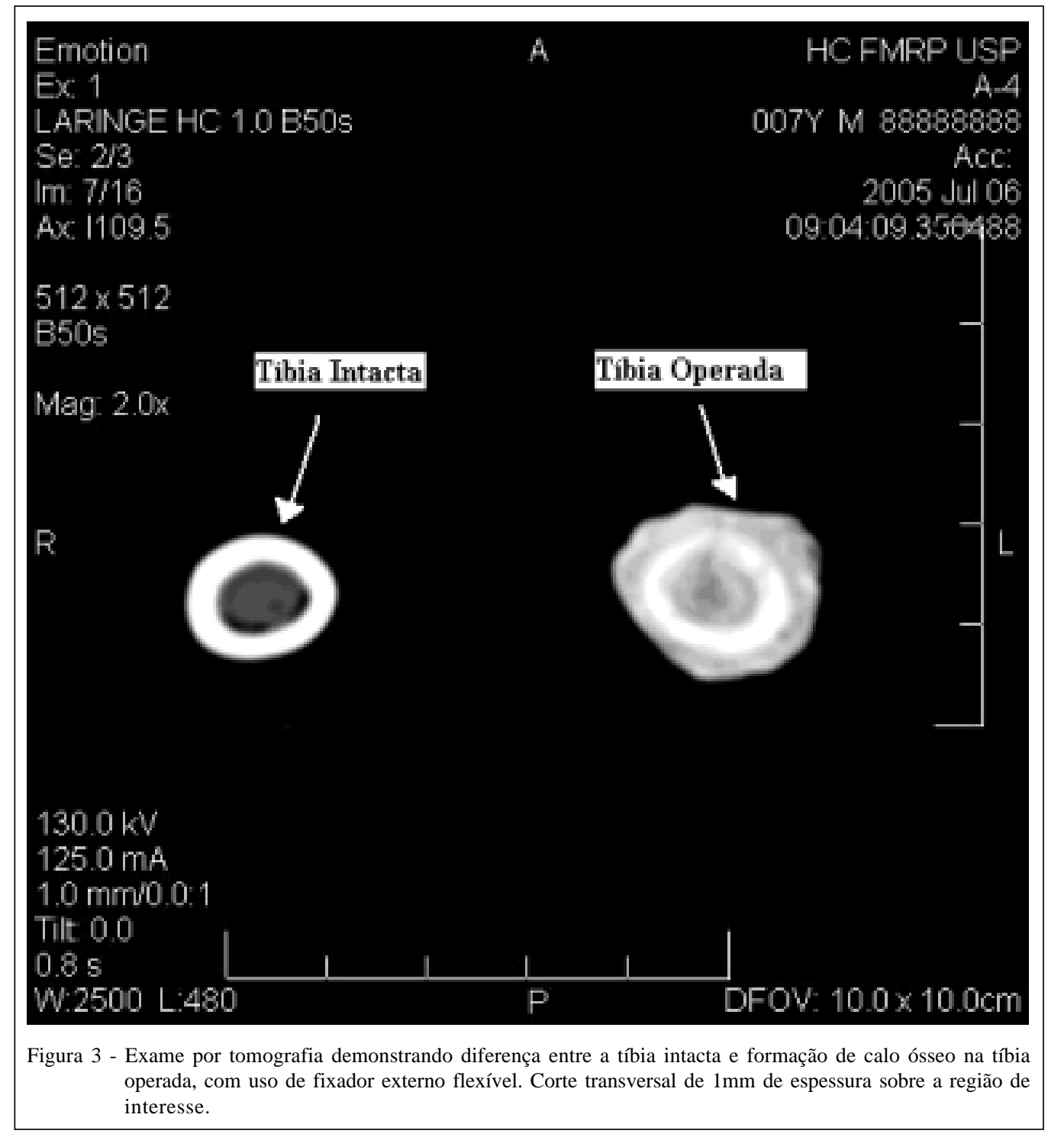

\section{RESULTADOS}

Para o grupo com consolidação de 30 dias, obteve-se uma porcentagem média de volume de calo periosteal de 202\%; para o grupo de 45 dias, a porcentagem média foi de 169,4\%; para o grupo de 60 dias, a porcentagem média foi de 187,4\%; e para o grupo de 90 dias, a porcentagem média foi de $138 \%$. Compararam-se os valores das porcentagens médias de volume de calo, obtidos das análises tomográficas, foi possível observar que houve diferenças significantes entre os grupos 30 e 45 dias, 30 e 60 dias, 30 e 90 dias, 45 e 90 dias e 60 e 90 dias $(\mathrm{P}<0,05)$, com exceção da comparação entre 45 e 60 dias $(\mathrm{P}>0,05)$.

Para o grupo com consolidação de 30 dias, obteve-se a destruição das tíbias intactas com uma média de força máxima de $1228,52 \pm 126,22 \mathrm{~N}$ e para as tíbias operadas de $192,47 \pm 37,54 \mathrm{~N}$; para o grupo de 45 dias, obteve-se a destruição das tíbias intactas com uma média de força máxima de 1230,63 \$102,18N e para as tíbias operadas de $594,89 \pm 91,39 \mathrm{~N}$; para o grupo de 60 dias, obteve-se a destruição das tíbias intactas com uma média de força máxima de 992,67士24,42N e para as tíbias operadas de $616,86 \pm 83,26 \mathrm{~N} \mathrm{e}$; para o grupo de 90 dias, obteve-se a destruição das tíbias intactas com uma média de força máxima de 1340,81ะ64,22N e para as tíbias operadas de $1169,08 \pm 100,32 \mathrm{~N}$.

Compararam-se os valores das médias obtidas dos ensaios mecânicos, que demonstraram haver diferenças significantes entre os grupos operados aos 30 e 45 dias, 30 e 60 dias, 30 e 90 dias, 45 e 90 dias e 60 e 90 dias $(\mathrm{P}<0,05)$. Todas as comparações 
entre os grupos respectivos intactos e operados demonstraram diferenças significantes $(\mathrm{P}<0,05)$, com exceção do grupo 90 dias ( $\mathrm{P}>0,05)$.

\section{DISCUSSÃO}

O emprego dos fixadores externos em animais não é novo, sendo atualmente rotineira a sua utilização, mas, por outro lado, ainda geram dúvidas principalmente quanto à sua adequação ao longo do tempo, devido à dificuldade de contenção dos animais, que descarregam peso sobre o membro fraturado, ao contrário dos humanos. Uma das razões para isso talvez seja o tipo de fixador. A principal meta do presente estudo foi o desenvolvimento de um fixador externo robusto, mas flexível, que permitisse a dinamização do foco da fratura pela transmissão axial cíclica da carga. A dinamização se manifesta por micro-movimentos que comprovadamente estimulam a consolidação, pois produzem o chamado calo ósseo irritativo (SCHMIDT \& RORABECK, 1983; DE BASTIANI et al., 1984; WU et al., 1984; WOLF et al., 1998; CLAES et al., 2000; AUGAT et al., 2001). Micro-movimentos são, portanto, benéficos, ao contrário dos macro-movimentos, que destroem o calo ósseo em formação e resultam nos defeitos da consolidação, como o retarde, patente aos três meses, e a pseudoartrose, patente aos seis meses após a fratura.

Fixadores externos rígidos mantêm os fragmentos ósseos afastados e também podem, facilmente, levar ao defeito de consolidação. Esses fixadores podem ser dinamizados pelo afrouxamento das peças de conexão, mas essa manobra não permite quantificar a magnitude da dinamização, que pode ser para mais ou para menos do que o desejável. Com o uso de uma haste flexível, cujo grau de deformação já é conhecido, o risco de ocorrência de um defeito de consolidação é mínimo (SCHMIDT \& RORABECK, 1983), fato comprovado neste estudo, no qual nenhum osso deixou de consolidar. O mesmo não ocorreu quando se utilizou um fixador externo rígido e outro flexível dinamizado pelo afrouxamento das conexões para reduzir osteotomias de fêmures de ratos. Neste estudo, as osteotomias reduzidas com fixador rígido consolidaram mais rapidamente do que as reduzidas com o fixador flexível (RÖNTGEN et al., 2010), possivelmente devido ao afrouxamento excessivo do fixador, mesmo quantificando-o previamente. Acreditase que, no decorrer do pós-operatório, o afrouxamento possa aumentar, o que não aconteceria com uma haste de flexibilidade pré-determinada. Em outro estudo, no qual foram utilizados dois tipos de fixadores, um com haste mais flexível, que necessitava de uma carga de
$183 \mathrm{~N}$ para deslocar $1 \mathrm{~mm}$, e outro mais rígido, que para o mesmo deslocamento necessitava de 388N, os autores concluíram que o primeiro induzia à formação de um calo ósseo mais exuberante (KRISCHAK et al., 2002). Os ensaios mecânicos realizados no presente estudo demonstraram que um deslocamento axial de $1 \mathrm{~mm}$ foi produzido por uma carga de $77 \mathrm{~N}$ com a haste flexível, enquanto que a haste rígida (comparativa) necessitava de uma carga aproximada de 134N.

Os carneiros foram escolhidos como animais de experimentação para este estudo devido à ausência da fíbula, que proporciona a incidência da carga exclusivamente sobre a tíbia, facilitando a interpretação dos resultados. O modelo da osteotomia transversal foi selecionado por representar o tipo de fratura que apresenta a maior dificuldade em consolidar, sendo aquela que mais facilmente leva aos defeitos de consolidação (KRISCHAK et al., 2002).

O acompanhamento radiográfico pósoperatório foi realizado a cada duas semanas, como preconizado por FOSSUM et al. (2002) e o tomográfico, juntamente com o ensaio mecânico destrutivo, ao final do período de observação de cada grupo experimental. Os ensaios mecânicos realizados demonstraram haver uma relação entre a consolidação óssea e a resistência mecânica, em relação ao tempo de avaliação, com diferenças significantes entre os grupos operados aos 30 e 45 dias, 30 e 60 dias, 30 e 90 dias, 45 e 90 dias e 60 e 90 dias $(\mathrm{P}<0,05)$. Todas as comparações entre os grupos respectivos intactos e operados foram significantemente diferentes $(\mathrm{P}<0,05)$, sendo que, aos 90 dias após o procedimento, observou-se uma semelhança da força suportada pelo osso intacto e pelo operado, sem diferença significativa $(\mathrm{P}>0,05)$. Pelos métodos de avaliação radiográfico e tomográfico, foi observada a formação de calo ósseo endosteal e periosteal volumoso, comprovando a eficácia do fixador externo utilizado, pois, segundo FOSSUM et. al. (2002), esses achados só seriam possíveis na presença de micro-movimentos no foco da fratura, neste caso, proporcionados pela haste flexível (Figura 3). Não foi observada reabsorção óssea na interface pino-osso, o que demonstrou que a haste flexível foi capaz de absorver as cargas que poderiam ser transmitidas aos pinos. O aumento da porcentagem média do volume de calo periosteal encontrado no grupo 60 dias, que superou o grupo 45 dias, não foi significante. Contudo, esse fato pode ter ocorrido pelo processo de substituição tecidual que se segue ao longo de uma consolidação de fratura. A diminuição significante da porcentagem média do volume de calo periosteal no grupo 90 dias ocorreu devido ao processo de remodelagem haversiana, caracterizada pela forte 
consolidação já existente no foco da osteotomia e comprovada pelo ensaio mecânico destrutivo (FOSSUM et al., 2002).

\section{CONCLUSÃO}

O fixador externo flexível desenvolvido e utilizado neste estudo mostrou-se confiável, pois possibilitou estabilidade entre os segmentos ósseos, propiciando o reparo no foco da fratura com desenvolvimento de calo periosteal mais volumoso em todos os animais, com a vantagem de ser econômico e de fácil obtenção. Diante dos resultados obtidos, esse fixador é recomendável para o tratamento de fraturas dos ossos longos de animais de médio porte na cirúrgica veterinária.

\section{AGRADECIMENTOS}

Os autores agradecem aos técnicos Francisco Carlos Mazzocato e Luiz Henrique Pereira, pela ajuda na condução experimental. Este estudo foi financiado pela Fundação de Amparo à Pesquisa do Estado de São Paulo (FAPESP), Processo n.2008/55342-5.

\section{COMITÊ DE ÉTICA E BIOSSEGURANÇA}

O trabalho foi aprovado pelo comitê de ética no uso de animais de experimentação da FMRP-USP, em sua $8^{\text {a }}$ reunião ordinária de 29 de setembro de 2003.

\section{REFERÊNCIAS}

AUGAT, P. et al. Mechanical stimulation by external application of cyclic tensile strains does not effectively enhance bone healing. Journal of Orthopaedic Trauma, v.15, n.1, p.54-60, 2001. Disponível em: <http://www.ncbi.nlm.nih.gov/ pubmed/11147689>. Acesso em: 03 out. 2009.

CLAES, L. et al. Influence of size and stability of the osteotomy gap on the success of fracture healing. Journal of Orthopaedic Research, v.15, n.4, p.577-584, 1997. Disponível em: <http:/ /www.ncbi.nlm.nih.gov/pubmed/9379268>. Acesso em: 03 out. 2009.
CLAES, L. et al. Mechanical modification of callus healing. Der Chirurg, v.71, n.9, p.989-994, 2000. Disponível em: $<$ http://www.ncbi.nlm.nih.gov/pubmed/11043114>. Acesso em: 03 out. 2009.

DE BASTIANI, G. et al. The treatment of fractures with a dynamic axial fixator. Journal of Bone and Joint Surgery. British Volume, v.66, n.4, p.538-545, 1984. Disponível em: <http://www.ncbi.nlm.nih.gov/pubmed/6746689>. Acesso em: 03 out. 2009.

FOSSUM, TW. et al. Cirurgia de pequenos animais. São Paulo: Roca, 2002. 1335p.

GARCÍA-FINÃNA, M. et al. Comparison of MR imaging against physical sectioning to estimate the volume of human cerebral compartments. NeuroImage, v.18, n.2, p.505-516, 2003. Disponível em: <http://www.ncbi.nlm.nih.gov/pubmed/ 12595203>. Acesso em: 03 out. 2009.

KRISCHAK, GD. et al. Effects of one-plane and two-plane external fixation on sheep osteotomy healing and complications. Clinical Biomechanics, v.17, n.6, p.470476, 2002. Disponível em: <http://www.ncbi.nlm.nih.gov/ pubmed/12135549>. Acesso em: 03 out. 2009.

RÖNTGEN, V. et al. Fracture healing in mice under controlled rigid and flexible conditions using an adjustable external fixator. Journal of Orthopaedic Research, v.28, n.11, p.1456-1462, 2010. Disponível em: <http://onlinelibrary.wiley.com/doi/ 10.1002/jor.21148/abstract>. Acesso em: 09 dez. 2010.

SCHMIDT, A.; RORABECK, CH. Fractures of the tibia treated by flexible external fixation. Clinical Orthopaedics and Related Research, v.178, p.162-172, 1983. Disponível em: $<$ http://www.ncbi.nlm.nih.gov/pubmed/6883847>. Acesso em: 03 out. 2009.

WOLF, S. et al. The effects of external mechanical stimulation on the healing of diaphyseal osteotomies fixed by flexible external fixation. Clinical Biomechanics, v.13, n.4-5, p.359-364, 1998. Disponível em: <http://www.ncbi.nlm.nih.gov/pubmed/ 11415808>. Acesso em: 03 out. 2009.

WU, JJ. et al. Comparison of osteotomy healing under external fixation devices with different stiffness characteristics. Journal of Bone and Joint Surgery. American Volume, v.66, n.8, p.1258-1264, 1984. Disponível em: <http:// www.ncbi.nlm.nih.gov/pubmed/6490701>. Acesso em: 03 out. 2009. 